\title{
Desenvolvimento e aplicação de um material paradidá- tico interativo como auxiliar no ensino de conceitos básicos de termologia ${ }^{+*}$
}

Daniel Fernandes Mendes da Silva

Centro Universitário Augusto Motta - UNISUAM

Sérgio Eduardo Silva Duarte

CEFET-RJ

Rio de Janeiro - RJ

\section{Resumo}

Neste artigo relatamos o desenvolvimento e a aplicação de um material paradidático digital interativo, que tem o objetivo de auxiliar o estudo de termologia. O material contém, além de textos didáticos, animações na linguagem Macromedia Flash inseridas num arquivo PDF. Comentamos sobre a aplicação e boa recepção do material por alunos de uma turma de $1^{a}$ série do ensino médio.

Palavras-chave: Animações. Material paradidático. Modelo corpuscular. Termologia.

\begin{abstract}
We report the development and implementation of an interactive digital paradidactic material, which aims to aid the study of Thermology. The material contains, in addition to textbooks, 11 animations in Macromedia Flash language inserted into a PDF file, which is freely available on the internet. We comment on the
\end{abstract}

\footnotetext{
${ }^{+}$Development and implementation of an interactive paradidactic material to assist in teaching basic concepts of Thermology

* Recebido: julho de 2013.

Aceito: maio de 2014.
} 
application and good reception of the material by students in a High School $1^{\text {st }}$ grade class.

Keywords: Animations. Paradidactic materials. Corpuscular Model. Thermology.

\section{Introdução}

A aceleração da tecnologia no campo da informação e comunicação pressiona a escola por mudanças nas relações envolvendo ensino/aprendizagem. A informática na escola coloca os estudantes frente a um novo processo educativo, onde podem prosseguir, frear, voltar, reestudar ou aprimorar conceitos vistos em sala de aula, aprofundar e criar suas investigações e interpretações sobre o assunto, baseados em outras informações pesquisadas ou discutidas com diferentes autores ou colegas, via internet.

O cenário tecnológico escolar é, muitas vezes, desconexo com a realidade fora da sala de aula. Vivemos uma época de grandes avanços tecnológicos, na qual a nova geração de jovens tem os computadores, em geral, como um instrumento básico de comunicação, diversão e aquisição de informações. Todavia, tal recurso ainda precisa encontrar seu espaço como ferramenta potencialmente útil para auxiliar uma aprendizagem mais efetiva de conceitos e construção de habilidades, tanto no mundo em geral, quanto no Brasil, em particular (ARAUJO I. S. et al, 2012).

A esse respeito, os $\mathrm{PCN}+$ dizem que:

A escola não pode ficar alheia ao universo informatizado se quiser, de fato, integrar o estudante ao mundo que o circunda, permitindo que ele seja um indivíduo autônomo, dotado de competências flexíveis e apto a enfrentar as rápidas mudanças que a tecnologia vem impondo à contemporaneidade (BRASIL, 2009).

O computador é um poderoso instrumento de aprendizagem e pode ser um grande parceiro na busca do conhecimento, podendo ser usado como uma ferramenta de auxílio no desenvolvimento cognitivo do estudante, desde que se consiga disponibilizar um ambiente de trabalho, onde os alunos e o professor possam desenvolver aprendizagens colaborativas, ativas, facilitadas, que propiciem ao aprendiz construir a sua própria interpretação acerca de um assunto, interiorizando as informações e transformando-as de forma organizada (FILHO; HECKLER; SARAIVA, 2007).

da Silva, D. F. M. e Duarte, S. E. S. 
Para Andrade, Macêdo e Dickman (2012), o computador tem provocado uma grande revolução na educação devido a sua capacidade de ensinar, trazendo possibilidades de implantação de novas técnicas de ensino praticamente ilimitadas, principalmente no que diz respeito às ciências. Dessa maneira, a escola deve passar a viver em consonância com a realidade externa aos seus portões.

A demanda por uma solução moderna e eficaz leva-nos ao conceito de software educacional. O desenvolvimento de um sistema que crie um ambiente no qual o usuário seja capaz de modelar, visualizar e interagir com a simulação proposta baseada em experimentos da Física real poderia ser considerado como uma solução para suprir esta demanda. Tal sistema seria uma ferramenta complementar para o estudo da Física, desde que através dele seja possível a realização de experimentos "virtuais" com a finalidade de esclarecer e reforçar o conhecimento teórico da Física, no nosso caso a teoria corpuscular da matéria (Ibid).

$\mathrm{O}$ modelo atômico da matéria tem papel central em uma parte importante dos conteúdos de física, e de química, nos ensinos fundamental e médio dedicados a explicar a natureza e as propriedades da matéria e das mudanças que esta pode sofrer. Para que os estudantes se apropriem desse modelo e possam utilizá-lo na interpretação e previsão de fenômenos físicos é necessário que se esclareçam algumas considerações importantes de sua formulação mesmo da versão simplificada que é apresentada no ensino médio. Os estudantes, muitas vezes, têm dificuldade em associar a matéria em estado sólido de objetos que ele está habituado a manipular com o modelo que propõe que essa matéria é formada por átomos cuja massa se concentra em uma parte ínfima de seu volume e que toda estrutura está o tempo todo vibrando e em movimento. Assim, muitas vezes lhes parece pouco razoável essa descrição da matéria com uma natureza descontínua, e que para além de sua aparência visível ou dos diversos estados em que pode se apresentar, seja construída por pequenas partículas que estão em contínuo movimento e interação.

Contudo, segundo Pozo e Crespo (2009), mesmo que os alunos cheguem a vislumbrar, em algumas tarefas ou situações, a possibilidade de um mundo descontínuo oculto no mundo contínuo que enxerga diariamente, tende a voltar às teorias intuitivas, muito mais próximas do mundo que os rodeia. Assim, se as partículas fazem parte da matéria, atribuem a ela as mesmas propriedades do objeto ou do sistema de que fazem parte, sendo algo parecido a pequenos grãos ou pedaços dessa matéria. A matéria seria contínua tal como a vemos. Por sua vez o estado natural das coisas - incluindo essas partículas diminutas de que falam os livros e os professores - seria o repouso, de modo que elas só se moveriam se houvesse um agente ou causa externa que provocasse o movimento. 
A crença dos alunos a respeito da matéria é tal como vemos: contínua e estática. Em outras palavras, os alunos acabam explicando o funcionamento das partículas a partir das propriedades do mundo macroscópico, em vez de, como propõe a teoria atômico-molecular, explicar as propriedades do mundo macroscópico a partir do funcionamento das partículas.

$\mathrm{O}$ ensino de conteúdos associados à Física do século XX esbarra, entre outras coisas, na ausência de experimentos simples para discussão dos conceitos envolvidos. Em particular o movimento das partículas subatômicas. Para facilitar a percepção desse modelo físico que está longe de afetar nossos sentidos é comum a utilização de ilustrações mesmo para fenômenos dinâmicos. E sabemos que a interpretação desse fenômeno em particular por parte dos alunos, faz-se, na maioria das vezes, necessário o uso de imagens estáticas e a articulação gestual pelo professor. Assim, as animações e as simulações por computador seriam uma forte ferramenta no processo de ensino-aprendizagem.

A utilização destes mundos virtuais, pode também ajudar a esclarecer aspectos, às vezes sutis, de um sistema físico. Aliado a isso, temos o grande interesse demonstrado pelos alunos no manuseio do computador, e que pode ser canalizado para o aprendizado dos mais variados temas.

Uma das tarefas dos professores consiste em encontrar, por meio de produção própria ou utilização de materiais disponíveis, materiais didáticos adequados a seus estudantes. Estes materiais apresentam vários formatos: textos (livros ou outros), experimentos demonstrativos, experimentos com realização de medidas, vídeos ou outros recursos imagéticos. O computador é uma ferramenta que se mostra útil em várias dessas vertentes: com textos, com animações, com experiências simuladas, entre outras. A disseminação da internet faz com que esta ferramenta possa ser amplamente divulgada e multiplicada. As possibilidades de utilização de computadores em processos de aprendizagem são múltiplas. E, como ocorre com os materiais e ferramentas, sua utilização e eficácia são de difícil avaliação (BARROSO; FELIPE; PORTO, 2005).

O texto paradidático é uma ferramenta didática que pode contribuir sensivelmente para a ampliação conceitual do aluno, porém o processo envolvendo o trabalho didático em sala de aula requer uma adequação metodológica por parte do professor, na medida em que difere consideravelmente das aulas tradicionais. $\mathrm{O}$ professor, ao utilizar os textos alternativos no cotidiano escolar, deverá estar atento às leituras dos alunos, pois os mesmos provavelmente terão formas de interpretação que muitas vezes serão inesperadas. Isso pode levar o professor à reflexão acerca da sua postura didático-pedagógica, conscientizando-se de que a sua realidade de sala de aula precisará ser repensada constantemente. 
O tópico escolhido para este trabalho foi termologia, pois os conceitos básicos desse tema são entendidos e descritos pelos alunos de forma nem sempre precisa, como, por exemplo, o de temperatura e calor, que são interpretados como sendo a mesma coisa, que o calor comporta-se como um fluido material que pode passar de um corpo para outro e que a temperatura de um corpo depende de suas características macroscópicas (POZO; CRESPO, 2009), quando se deseja que seja compreendido o modelo da natureza descontínua da matéria e do movimento das partículas, isto é, como a análise microscópica das interações das partículas permitiria explicar o comportamento e a aparência macroscópica que a matéria apresenta.

Levando em conta os conhecimentos prévios dos alunos, foi desenvolvido um material paradidático digital interativo no formato PDF com o objetivo de auxiliar a apresentação das ideias presentes no estudo da Termodinâmica, e para isso foram utilizadas as animações e simulações - na linguagem Macromedia Flash - inseridas nesse arquivo.

\section{Desenvolvimento do Material}

As animações e simulações são consideradas, por muitos (ANDRADE; DICKMAN; MACÊDO, 2012; BARROSO; NEUMANN, 2005; SOUZA; NAZARÉ, 2012), a solução dos vários problemas que os professores de física enfrentam ao tentar explicar para seus alunos fenômenos demasiado abstratos para serem "visualizados" através de uma descrição em palavras, e demasiado complicados para serem representados através de uma única figura. Elas possibilitam observar em alguns minutos a evolução temporal de um fenômeno que levaria horas, dias ou anos em tempo real, além de permitir ao estudante repetir a observação sempre que o desejar.

Com base nas dificuldades associadas ao ensino de Termologia foi elaborado um material paradidático digital interativo para auxiliar o ensino desse tópico. O material criado apresentou inicialmente os conceitos básicos necessários à discussão da estrutura da matéria. Para isso foram criadas três animações na linguagem Macromedia Flash ilustrando, de forma simplificada, o modelo molecular da matéria e o movimento das partículas microscópicas na descrição dos estados sólido, líquido e gasoso. Outra animação, na mesma linguagem, ilustra a propagação de calor por condução, também com uma representação bastante simplificada da teoria corpuscular da matéria, mas que tenta enfatizar o movimento das partículas e suas interações, aspectos do modelo que nem sempre são claros para o aluno. Fo- 
ram obtidas outras animações e um vídeo (do movimento browniano) gratuitamente na internet e inseridas no material paradidático digital.

Para a criação dessas animações, inicialmente decidimos os elementos da teoria que seriam abordados, e então reunimos algum conhecimento técnico dos softwares utilizados e paciência para desenhar cada etapa do fenômeno e criar os diferentes frames a serem projetadas. Mostraremos, a seguir, alguns passos para o desenvolvimento das animações.

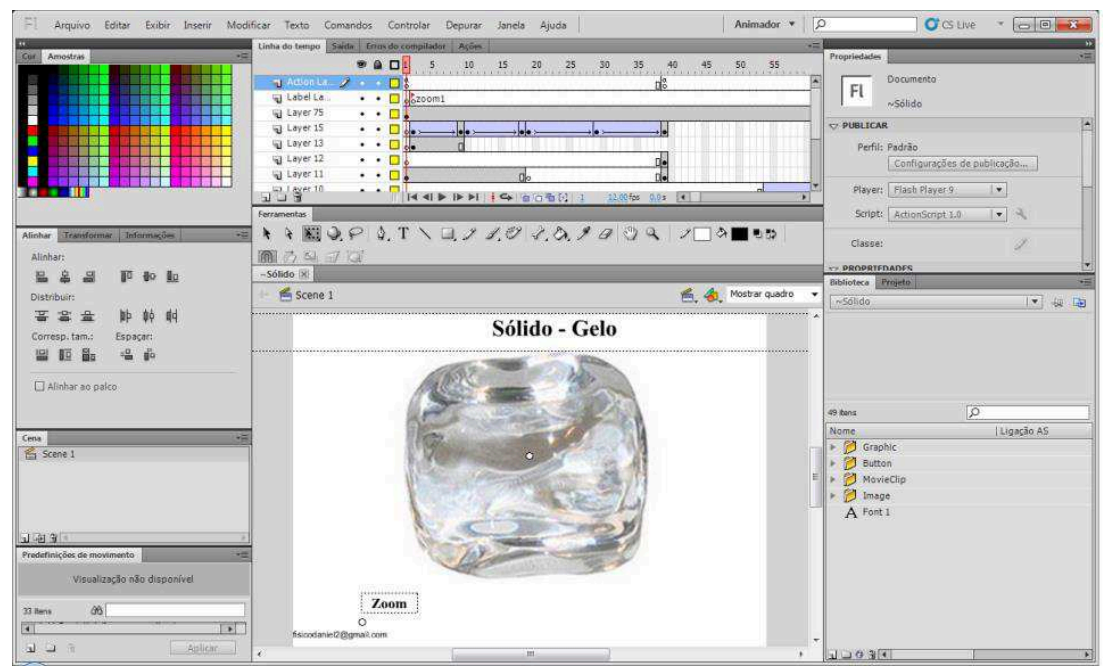

Fig. 1 - Desenvolvimento da animação da visão microscópica do gelo.

Os conceitos básicos relevantes foram desenvolvidos através de textos, de tal forma que o mesmo interagisse com as animações ao longo do material. O paradidático foi construído no formato PDF, possibilitando, assim, que o produto pudesse ser acessado pelo aluno a qualquer momento em qualquer computador, e não somente de posse do professor. Este material interativo pretende fornecer um mecanismo auxiliar na aprendizagem, ajudando a visualizar os conceitos que não são familiares ao estudante.

Para avaliar sua eficácia, foram colocadas cinco perguntas como um PréTeste e mais cinco perguntas como Pós-Teste. Essas perguntas são abertas, e contextualizadas (por exemplo, por que o mercúrio de um termômetro "sobe" quando aumenta a temperatura?), nas quais o aluno pode fazer espontaneamente a interpretação que for mais adequada para ele, e dentre essas perguntas foram usadas per- 
guntas que induziam alguns tipos de respostas (por exemplo, por meio de questionários objetivos nos quais se alternam respostas macroscópicas com respostas em termos da teoria corpuscular).

A animação da Fig. 2, em particular, tem como objetivo principal fazer com que os alunos diferenciem movimentos macroscópicos de um sólido (que no caso é o gelo) do movimento das partículas microscópicas que compõem o mesmo, segundo o modelo. Por isso, a visualização do movimento das partículas microscópicas, integrada em uma teoria cinético-molecular, facilita ao aluno a compreensão das mudanças que ocorrem na matéria Pozo e Crespo (2009). A Fig. 3 refere-se à animação da estrutura molecular do gelo (após iniciar e clicar no botão "zoom").

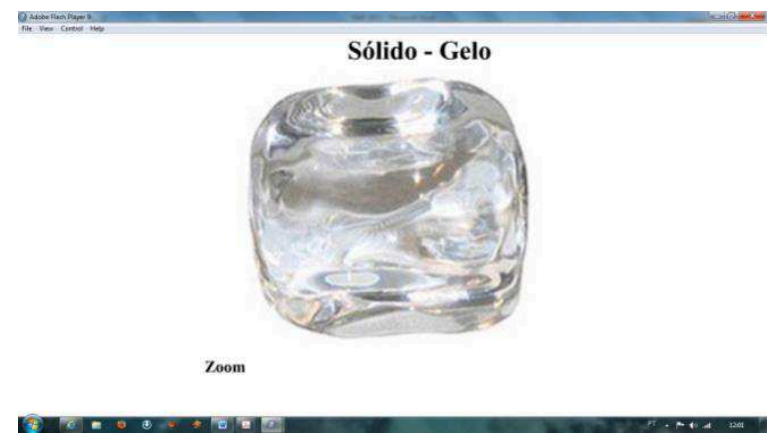

Fig. 2 - Visão macroscópica do gelo.

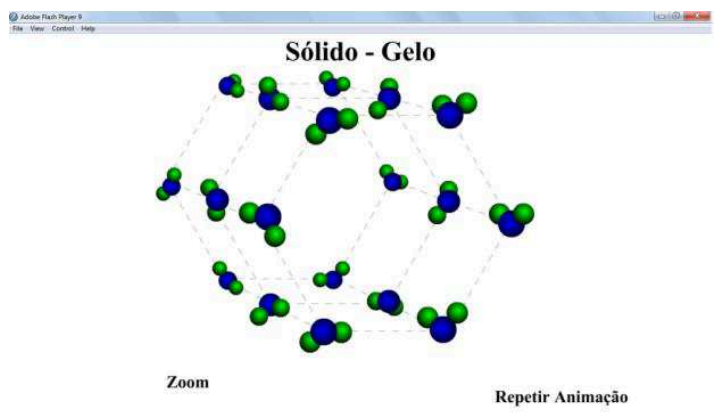

Fig. 3 - Visão microscópica do gelo.

O material paradidático digital está hospedado no site 4shared $<$ http://goo.gl/Clg0ol $>$ e pode ser usado por estudantes e professores, e as anima- 
ções pelos sites: <http://goo.gl/3KP6LC>, <http://goo.gl/2xcHQ7>, $<$ http://goo.gl/HVRg7y> e <http://goo.gl/JNHoa5>. Todos podem descarregar o programa e usá-lo em seu computador. Entretanto, para visualizar as animações é necessária uma atualização do Adobe Reader ${ }^{\circledR}$, no site $<$ http://www.adobe.com/br/>. Depois da descarga, é necessário apenas um duplo clique e o arquivo abre normalmente e as animações funcionam da mesma forma.

O material paradidático digital também faz uso de outros conteúdos de termologia, como dilatação térmica, convecção térmica e irradiação térmica, como mostra a Fig. 4, conteúdos esses que são acompanhados de animações para melhor entendimento por parte do aluno.

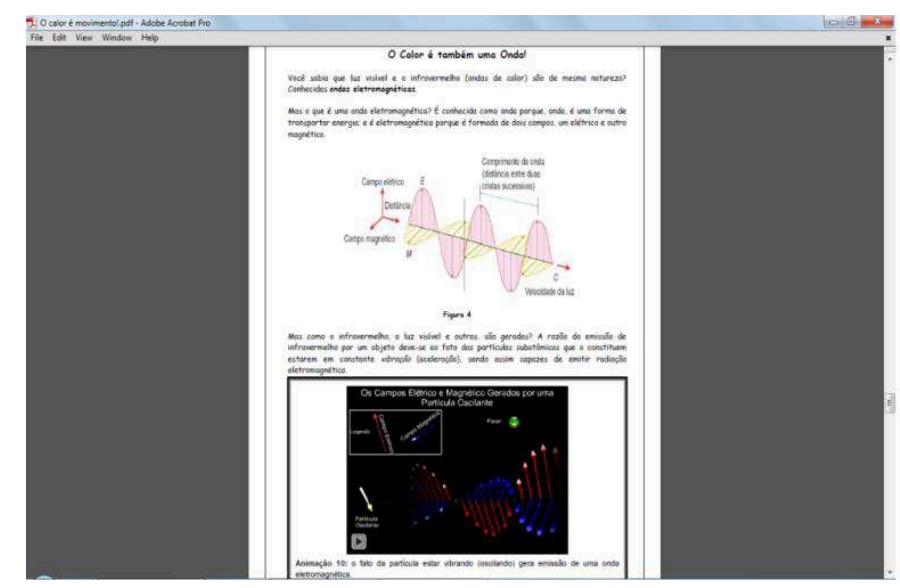

Fig. 4 - Página da propagação de calor por irradiação.

\section{Metodologia}

O material que desenvolvemos foi aplicado durante as aulas de física ministradas por um dos autores do presente trabalho, no ano letivo de 2012, para uma turma de $1^{\text {a }}$ série do ensino médio. A investigação dos conhecimentos prévios foi feita através da aplicação de um questionário aos alunos e posterior a leitura do material interativo.

O colégio onde foi aplicado o projeto tem uma característica bem peculiar: ele fornece bolsas de estudos para os melhores alunos da Rede Municipal de Educação do Rio de Janeiro de algumas escolas da região da Barra da Tijuca no município do Rio de Janeiro. Então, a primeira série do ensino médio, onde foi 
realizada a aplicação do material aqui apresentado, era uma turma heterogênea, no sentido socioeconômico. A escola contava com um espaço verde muito extenso, laboratório de ciências, sala de multimídia e laboratório de informática, em outras palavras, com uma boa estrutura física para auxiliar no processo de ensinoaprendizagem.

A quantidade de conteúdos propostos foi limitada pelo tempo disponível na disciplina de física. O professor dessa rede particular de ensino lecionava apenas dois tempos semanais de aulas em cada turma, com cada tempo possuindo 45 minutos, na segunda-feira. A estrutura curricular desenvolvida foi aplicada pelo autor do presente trabalho, nas mesmas turmas analisadas pelo questionário de conhecimentos prévios, no primeiro bimestre.

No dia 5 de março de 2012, foi instalado em todos os computadores da sala de informática o arquivo do material paradidático digital; posteriormente cada turma foi levada para a sala em seu tempo de aula. Foi pedido que a hipermídia, no formato PDF, fosse lida antes de responderem ao questionário posterior ao mesmo. Nesse dia, 30 dos 40 alunos matriculados das turmas de aplicação responderam ao questionário de conhecimentos prévios. Nem todos os alunos compareceram a aula no dia e os alunos presentes responderam ao questionário na sala de informática. Ainda na mesma aula, após responder e entregar o questionário de conhecimentos prévios, os alunos iniciaram a leitura do material paradidático digital. Alguns não concluíram a leitura até o final da aula, então foi solicitado que terminassem a leitura e a análise do mesmo em casa. Para isso, foi necessário que a hipermídia fosse inserida no espaço dos materiais didáticos no site da escola. Também poderia ter sido enviado por e-mail ou o aluno poderia ter acessado o site onde o material paradidático digital está hospedado.

Achamos importante comentar que no início da aula, no qual foi aplicado esse projeto, em alguns computadores as animações no paradidático não funcionavam. Então, foi constatado que o programa Adobe Reader estava desatualizado. Somente depois que o professor de informática do laboratório atualizou gratuitamente pelo site <http://www.adobe.com/> é que as animações contidas no material paradidático funcionaram.

O uso do material foi avaliado durante o processo de aplicação, pela observação respostas e comportamento dos alunos. Além disso, queríamos obter dados mais objetivos e precisos, por isso aplicamos um questionário de conhecimentos prévios, em busca de conhecimentos pré-existentes na estrutura cognitiva dos alunos que pudessem servir como subsunções para os conteúdos que queríamos ensinar, e um questionário de conhecimentos posteriores, aplicado após o término do uso do referido material em sala de aula. Juntamente a esses, desenvol- 
vemos e aplicamos um instrumento de avaliação qualitativa, coletando as opiniões dos alunos referentes na qualidade, importância, necessidade de mudança e metodologia utilizada na aplicação do material paradidático digital interativo.

A seguir, apresentaremos as questões do questionário de conhecimentos prévios e as distribuições de respostas dos cinco questionários respondidos pelos alunos. Também faremos uma breve análise de cada distribuição de respostas.

Questão 1 - Por que uma camisa, após ser lavada, seca quando é estendida ao Sol?

\section{Exemplos de respostas obtidas:}

“... o calor da radiação solar faz 'vibrar' as moléculas de água..."

“... o Sol agita as moléculas da água...”

“... o calor do Sol aquece a camisa molhada e ocorre a evaporação."

“... o calor do Sol evapora a água."

Diante da pergunta aberta acima do questionário, somente $30 \%$ dos alunos chegaram a se referir à composição corpuscular da matéria para explicar um fenômeno físico cotidiano.

As pesquisas a respeito da utilização por parte dos alunos do modelo corpuscular em suas explicações (POZO; GÓMEZ CRESPO; SANZ, 1993, 1999 apud POZO; CRESPO, 2009) mostram que existe uma porcentagem importante de indivíduos que enfrentam dificuldades na hora de entender a matéria como descontínua e de utilizar espontaneamente em suas explicações, independentemente do seu grau de instrução em Física e em Química.

Questão 2 - Você já deve ter notado que ao esfregar as mãos durante algum tempo elas ficam mais quentes. Isso ocorre por quê??

Algumas respostas obtidas:

“... há troca de energia entre as mãos, sendo assim compartilhando energia."

“... o atrito gera vibração das moléculas, gerando calor.”

"Por causa do atrito."

"Ao esfregar as mãos, o atrito existente se transforma em energia térmica, aumentando a temperatura." 
Além de darem algumas respostas erradas ou incompletas, os alunos apresentam certa dificuldade em utilizar o modelo microscópico da matéria em suas explicações.

Questão 3 - Se for colocado um ovo quente dentro de um copo com água fria, o que acontece? Explique em detalhes.

Na pergunta acima, houve respostas diversas, umas muito diretas, outras mais longas, porém nenhuma utilizando o modelo microscópico.

Algumas respostas obtidas:

"A água esquenta e o ovo perde calor, ou seja, trocam energia."

"O ovo irá esfriar e a água esquentar, pois o calor do ovo vai passar para a água."

“... a casca do ovo se desprende do interior...”

“... o ovo irá explodir..."

Alguns alunos, ao utilizarem os conceitos de "calor" ou "energia" demonstraram, através de suas respostas, que os mesmos são entendidos como algo material, uma substância, que pode ir de um corpo para outro.

Questão 4 - Por que o mercúrio do termômetro "sobe" quando aumenta a temperatura?

Algumas respostas obtidas:

"O mercúrio se dilata com o aumento de temperatura..."

"O mercúrio aquecido se dilata"

"O mercúrio sobe por que ocorre a agitação das moléculas de calor"

"O mercúrio 'foge' do calor liberado quando suas moléculas são agitadas"

Diante de perguntas abertas, reunindo situações cotidianas, como as quatro questões acima, nas quais o aluno pode fazer espontaneamente a interpretação que for mais adequada para ele, somente $20 \%$ das respostas chegam a se referir a composição corpuscular da matéria.

5. Temos um recipiente cheio de ar em que colocamos um balão na boca. Aquecemos o recipiente e vemos como o balão vai enchendo. Por que você acha que o balão encheu? 
a) As partículas de ar estão mais separadas umas das outras e por isso ocupam mais espaço.

b) Com a troca de calor, o ar dilata e ocupa mais espaço, por isso o balão enche.

c) Com a troca de calor, o ar concentra-se na parte de cima, no balão.

d) As partículas de ar dilatam-se com a troca de calor, e, ao aumentar de tamanho, precisam de mais espaço.

Neste caso, vemos que metade dos alunos optou pela resposta macroscópica C (50\%), seguida (30\%) da resposta microscópica correta (A). Sendo assim, quando induzida, a porcentagem de respostas microscópicas tende a aumentar.

Induzindo de alguma maneira esse tipo de resposta (por exemplo, por meio de questionário múltipla escolha nos quais se alternam respostas macroscópicas com respostas em termos da teoria corpuscular), as respostas microscópicas aumentam, apesar de, neste caso, geralmente aparecerem acompanhadas por outras interpretações baseadas nas próprias concepções dos alunos, de modo que a representação resultante aparece confusa, devido à uma assimilação acrítica e superficial do modelo corpuscular, misturando a informação proporcionada pela instrução como suas próprias concepções prévias.

Em seguida, apresentaremos as questões do questionário de conhecimentos posteriores e as distribuições de respostas dos cinco questionários respondidos pelos alunos, e uma breve análise de cada distribuição de respostas.

Questão 1 - Explique por que um satélite quando entra em rota de colisão com a Terra, sua parte frontal aquece?

Algumas respostas obtidas:

"Por que gera calor devido ao atrito..."

"... o trabalho realizado pela força de atrito com o ar..."

“... o choque entre as moléculas da atmosfera e do satélite gera calor..."

Nessa questão, poucos alunos (30\%) utilizaram o modelo microscópico para explicar esse fenômeno físico.

Questão 2 - Por que a pressão de um gás fechado em um recipiente rígido aumenta quando a temperatura cresce?

Algumas respostas obtidas:

“... as moléculas aumentam de tamanho..."

da Silva, D. F. M. e Duarte, S. E. S. 
"Nos gases, as moléculas se movimentam livremente..."

"Com o aumento de temperatura, as moléculas do ar vibram com mais intensidade, se afastando umas das outras, aumentando a pressão interna."

“... as moléculas de ar se dilatam..."

Observa-se nas respostas acima que os alunos confundem os níveis macroscópicos e microscópicos, atribuindo às partículas propriedades que correspondem ao nível macroscópico ou aparente, isto é, "as moléculas se dilatam", "as partículas aumentam de tamanho", "as partículas evaporam".

Questão 3 - Considere uma bala de revolver atirada contra um bloco de madeira. Após o choque, a bala e a madeira ficam aquecidas. Explique esse fato.

Algumas respostas obtidas:

“... ocorre atrito entre a bala e madeira, que se transforma em energia térmica..."

"O calor é a transferência de energia cinética entre as partículas. Com o atrito entre a bala e a madeira, as moléculas de ambas são sacudidas, passando a um estágio de vibração maior..."

Os $80 \%$ dos alunos que não fizeram uso em suas respostas do modelo corpuscular, utilizaram termos como "atrito", "energia", "calor". Isso nos remete à aquilo que Pozo e Crespo (2009) afirmam sobre a crença dos alunos: que para a maioria dos alunos, a energia é um conceito que sempre está ligado à atividade e aos seres vivos. Com a troca de calor, os alunos atribuem propriedades materiais ao calor e consideram que é um tipo de substância que pode passar de um corpo para outro.

Questão 4 - Em trilhos consecutivos de uma estrada de ferro existe um espaçamento devido aos dias de diferentes temperaturas. Explique o motivo desse espaçamento.

\section{Algumas respostas obtidas:}

"Com o aumento de temperatura, o espaço entre as moléculas aumenta, ocorrendo dilatação"

"Por que o metal dilata no calor..."

“... no calor, o ferro dilata, assim as moléculas tendem a oscilar mais rápido e consequentemente se afastam umas das outras" 
"Por que em dias quentes... ocorrendo o espaçamento entre os trilhos."

Houve uma porcentagem maior de alunos (40\%), nessa questão, que utilizou o modelo corpuscular da matéria para explicar um fenômeno físico.

Questão 5 - Quando deixamos uma bola ao sol observamos que com o passar do tempo ela fica mais cheia. Por que você acha que isso acontece?

a) Porque com a troca de calor, as partículas de ar que estão dentro da bola se movimentam mais depressa, ocupando mais espaço e a bola enche.

b) Porque com a troca de calor, o ar presente no interior da bola sofre uma dilatação, ocupando mais espaço, e a bola enche.

c) Porque o calor faz com que aumente a quantidade de ar que há no interior da bola e por isso ela está mais cheia.

d) Porque com a troca de calor, as partículas de ar que estão dentro da bola dilatam, precisam de mais espaço e por isso a bola enche.

Induzindo o tipo de resposta, alternando respostas macroscópicas com respostas em termos da teoria corpuscular, as respostas microscópicas aumentaram (60\%), assim como na questão 5 do questionário de conhecimentos prévios, que tinha o mesmo princípio da questão acima.

Foi constatado (POZO; GÓMEZ; CRESPO, 1999 apud POZO; CRESPO, 2009) que a utilização do modelo corpuscular é afetada pela dificuldade e pelo conteúdo da tarefa. Esses alunos do Ensino Médio quando precisam optar entre diversas respostas tendem a escolher mais frequentemente o modelo corpuscular, ainda que de maneira errônea, quando aumenta a complexidade da tarefa. Eles utilizam esse modelo corpuscular em maior proporção quando se trata de explicar um fenômeno do que quando se trata de descrevê-lo (ibid.), fundamentando, assim, os resultados das questões 5 dos questionários.

De acordo com os resultados analisados, verificamos um ganho significativo de aprendizagem em algumas questões do projeto, pois o número de repostas que utilizaram termos microscópicos para explicar questões de termologia, em quatro das cinco questões, aumentou significativamente.

Sem dúvida, a impressão que tivemos quanto ao primeiro contato dos alunos com o projeto foi muito positiva. Eles olharam todo o paradidático, iniciaram as animações e se mostraram interessados em analisar o material paradidático. $\mathrm{Na}$ rede pública e na rede particular de ensino, sabemos que alguns estudantes possuem pouco interesse pelos estudos "tradicionais". Portanto, nesse contexto, torna-se 
propício o desenvolvimento dessa ferramenta auxiliar, que teve como objetivo tornar a aprendizagem mais participativa e ativa em sala de aula, independentemente de estudos paralelos.

O posicionamento aberto dos alunos sobre pontos fortes vistos frente ao uso do material nos mostra que os pontos positivos destacados são: a questão da interatividade, o uso das animações, o vídeo, a praticidade de acesso aos conteúdos e a motivação despertada para as aulas de física.

\section{Considerações finais}

Conseguimos, através do material desenvolvido, apresentar os conteúdos de termologia de uma forma mais atraente e ilustrativa do que os simples exercícios propostos ou as meras descrições de fenômenos efetuadas na maioria das aulas tradicionais, propiciando assim o maior envolvimento dos alunos nas aulas de física. $\mathrm{O}$ uso de animações e simulações permitiu a abordagem de um número maior de fenômenos num intervalo de tempo menor e proporcionou um enriquecimento da visão do modelo adquirida pelo aluno.

Esse trabalho foi desenvolvido com o objetivo de investigar as possibilidades de produção de material didático interativo complementar na forma de arquivos em PDF. Sendo assim, o uso da linguagem Flash na física está se revelando propícia, pois permite uma ampla gama de recursos visuais que, associados aos conceitos, sendo trabalhados na forma de experimentos, discussão de textos e vídeos, permite uma integração entre gráficos, imagens em movimento, medidas, e outros. Estas linguagens possibilitam uma ampla gama de utilização, principalmente na elaboração de materiais para ensino a distância.

Ao analisarmos as opiniões de nossos alunos, percebemos que estes materiais vão ao encontro da realidade da grande maioria deles, proporcionando um ambiente de estímulo, motivação e envolvimento no processo de ensino/aprendizagem, fazendo com que os alunos participem ativamente da aquisição de informações e construção do conhecimento. E, um ponto muito positivo percebido com tais ferramentas, é que despertou um maior interesse pelas aulas de física na visão dos alunos.

Uma das vantagens, constatadas pelos professores/pesquisadores, era que a construção de um material de autoria própria preenchia algumas lacunas deixadas pelos livros didáticos, ou apostilas, adotadas naquela série para o ensino de termologia; além disso, proporcionou aos autores um aprendizado em algumas ferramentas computacionais que viabilizará a construção de outros materiais paradidáticos interativos relacionados a outros conteúdos, proporcionando um aumento no núme- 
ro de materiais para o auxilio no ensino de Física. Outro ponto positivo constatado foi que um maior número de alunos passou a utilizar termos microscópicos (como átomos, moléculas, partículas) para explicar fenômenos relacionados à termologia após a leitura do material paradidático interativo.

Entretanto foi verificado que o computador apresenta algumas desvantagens ao ser usado como recurso didático, entre as quais a mais notável é a facilidade de distração. Além do forte apelo apresentado pelas imagens móveis, de certa maneira, desestimular a leitura dos textos explicativos, levando os alunos a ficarem apenas observando as imagens e as simulações no material, também existe a grande possibilidade de eles desviarem totalmente sua atenção do assunto da aula para utilizar outros recursos disponibilizadas pelo computador, que podem ser mais atraentes do que a aula (SOUZA; NAZARÉ, 2012).

É importante ressaltar que não encaramos o material aqui apresentado como um produto acabado. Ao longo do seu desenvolvimento e implantação percebemos, entre outros aspectos, que os textos teóricos têm muito a serem melhorados; também deixamos para um trabalho futuro o estudo e o desenvolvimento de uma proposta de outros materiais didáticos interativos, como este aqui apresentado, com temas que exijam um alto grau de abstração para que sirva a alunos e professores como uma ferramenta auxiliar no processo de ensino-aprendizagem.

\section{Referências bibliográficas}

ARAUJO, I. S.; BRANDÃO, R. V.; MULLER, M. G.; VEIT, E. A. Implementação do método de ensino peer instruction com o auxílio dos computadores do projeto "UCA" em aulas de Física do Ensino Médio. Caderno Brasileiro de Ensino de Física, v. 29, n. Especial 1, p. 491-524, set. 2012.

BRASIL. Ministério da Educação, Secretaria de Educação Média e Tecnológica (Semtec). Parâmetros Curriculares Nacionais para o Ensino Médio. Brasília: MEC/Semtec, 1999.

FILHO, K. S. O.; HECKLER, V.; SARAIVA, M. F. Uso de simuladores, imagens e animações como ferramentas auxiliares no ensino/aprendizagem de óptica. Revista Brasileira de Ensino de Física, v. 29, n. 2, p. 267-273, 2007.

ANDRADE I. S. F.; DICKMAN A. G.; MACÊDO J. A. Simulações computacionais como ferramentas para o ensino de conceitos básicos de eletricidade. Caderno Brasileiro de Ensino de Física, v. 29, n. Especial 1, p. 562-613, set. 2012. 
POZO, J. I.; CRESPO, M. A. G.. A aprendizagem e o ensino de ciências: do conhecimento cotidiano ao conhecimento cientifico. 5. ed. Porto Alegre: Artmed, 2009.

BARROSO, M.; FELIPE, G.; PORTO, C. M. Simulações computacionais no ensino de relatividade restrita. In: SIMPÓSIO NACIONAL DE ENSINO DE FÍSICA, XVI, 2005, Rio de Janeiro. Atas...

BARROSO, R.; NEUMANN, R. Simulações computacionais e animações no ensino de oscilações. In: SIMPÓSIO NACIONAL DE ENSINO DE FÍSICA, XVI, 2005, Rio de Janeiro. Atas...

SOUZA, A. M.; NAZARÉ, T. S. A utilização de um programa de computador para simulações de experimentos de óptica como forma de promover o aprendizado das ciências exatas. Física na Escola, v. 13, n. 1, 2012.

SILVA, D. F. M. A construção e aplicação de um paradidático digital interativo para o ensino de termologia. 2013. Dissertação (Mestrado Profissional em Ensino de Ciências e Matemática) - CEFET/RJ, Rio de Janeiro. 